\title{
Incidencias del proceso histórico en el proceso educativo argentino ${ }^{1}$
}

\author{
William Roberto Daros ${ }^{2}$ \\ Universidad del Centro Educativo Latinoamericano (Argentina) \\ Consejo Nacional de Investigaciones Científicas y Técnicas (Argentina) \\ daroswr@yahoo.es
}

Recepción: 08/07/2013

Evaluación: 20/10/2013

Aceptación: 13/12/2013

Artículo de Revisión

DOI: http:/ / dx.doi.org/ 10.9757/Rhela.22/03

\section{RESUMEN}

El artículo aporta una relación panorámica y conceptual sobre la educación argentina. En él se presentan los inicios de las propuestas educativas, la presencia de la visión positivista, la legislación sobre la educación en el siglo XIX, la presencia estudiantil universitaria, la incidencia de la dictadura militar, un proyecto posterior de país que tendía al desarrollo industrial y la correspondiente legislación federal de educación. La metodología empleada en este artículo consiste en recurrir a datos históricos -sin hacer una historia de la educación- del proceso educativo formal en Argentina, a fin de sostener la hipótesis de que este se ha constituido sobre una doble vertiente cuya sombra se extiende hasta el presente. Para lograr este objetivo y corroborar esta hipótesis se ponen de manifiesto: a) cómo las situaciones históricas, por medio de sus pensadores y políticos y de su legislación más representativa, b) inciden en el presente del proceso educativo argentino, referido especialmente al nivel primario $\mathrm{y}$ secundario, c) al generar una forma de ser sociocultural peculiar. No se pretende, pues, hallar una novedad histórica sino una forma de lectura diferente, para lograr tener conciencia acerca de cómo: a) las decisiones políticas y culturales, b) tomadas en el pasado c) no han sido inofensivas, d) lo que es una lección para el presente. Estas referencias históricas hacen visibles las pugnas que, dentro de la misma sociedad argentina, los bandos protagonistas iban generando. Estos fueron primeramente pro religiosos o pro laicos; y luego estos bandos se convirtieron en el federal y el unitario, no exento de corrupción, que perduran hasta el presente, en una no siempre fácil convivencia nacional.

Palabras clave: Revista Historia de la Educación Latinoamericana historia, educación, Argentina, dicotomías.

\footnotetext{
1 El autor agradece el otorgamiento de una beca a la Universidad Adventista del Plata (UAP - Entre Ríos, Argentina), que hizo posible este trabajo, el cual se encuadra en el texto mayor de un libro de próxima edición. En este libro se hallan explicitadas algunas afirmaciones y conclusiones solo enunciadas aquí, dados los límites que impone un artículo.

2 Doctor en Filosofía, profesor en Letras (Córdoba), licenciado en Filosofía (Rosario). Actualmente es docente de filosofía e investigador principal en la Universidad del Centro Educativo Latinoamericano (UCEL), del Consejo Nacional de Investigaciones Científicas y Técnicas (CONICET). Forma parte, además, del Comité de Pares de la Comisión Nacional de Evaluación y Acreditación Universitaria (CONEAU) y de la Agencia Nacional de Promoción Científica y Tecnológica (ANPCyT), Ministerio de Cultura y Educación.
} 


\section{Incident of the historical process in the argenti- ne an educational process}

\section{ABTRACT}

The article provides an overview and conceptual relationship on the Argentinean education. It presents the beginnings of the educational proposals, the presence of the positivist perspective, legislation on education in the nineteenth century, the university student presence, the incidence of the military dictatorship. A later project of country that tended to the industrial development and the corresponding federal law of education. The methodology used in this article, is to use historical data - without making a history of education - of the formal education process in Argentina in order to sustain the hypothesis that this has been set up on a double strand whose shadow extends up to the present. To achieve this goal and to check this hypothesis are evident: a) as the historical situations, through its thinkers and politicians and their more representative legislation, (B) How these have an impact on the present of the Argentinean educational process, in relation with particular to the primary and secondary level, c) generating a way sociocultural particular being. It is not intended to, therefore, to find a historical novelty; but a different way of reading, raising awareness about how to: a) the political and cultural decisions, B) taken in the past c) have not been harmless, d) What is a lesson for the present. These historical references make visible the struggles that, within the same Argentine society, the sides protagonists were generating. These were primarily religious pro or pro lay; and then these sides became in the federal and unitary, corrupted though, which lasted up to the present, not always in a national easy coexistence.

Key words: Journal History of the Latin American Education history, education, Argentina, dichotomies.

\section{Incidências do processo histórico no processo educativo Argentino}

RESUMO

O artigo contribui com uma relação panorâmica e conceitual sobre a educação argentina. Nele se apresentam os inícios das propostas educativas, a presença da visão positivista, a legislação sobre a educação no século XIX, a presença estudantil universitária, a incidência da ditadura militar, um projeto posterior de país que tendia ao desenvolvimento industrial e a correspondente legislação federal de educação. A metodologia empregada neste artigo consiste em recorrer a dados históricos - sem fazer uma história da educação - do processo educativo formal na Argentina a fim de sustentar a hipótese de que este se constituiu sobre uma dupla vertente cuja sombra se estende até o presente. Para alcançar este objetivo e corroborar esta hipótese se coloca em evidência: a) como as situações históricas, através de seus pensadores e políticos e de sua legislação mais representativa, b) incidem no presente do processo educativo argentino, referido especialmente ao nível primário e secundário, c) gerando uma forma de ser sociocultural peculiar. Não se pretende, pois, falar uma novidade histórica; senão uma forma de leitura diferente, fazendo tomar consciência acerca de como: a) as decisões políticas e culturais, b) tomadas no passado c) não foram inofensivas, d) o que é uma lição para o presente. Estas referências tornam visíveis as lutas que, dentro da mesma sociedade argentina, os grupos protagonistas iam gerando. Estes foram primeiramente pró-religiosos ou pró-laicos; e logo estes grupos se converteram no federal e no unitário, não isento de corrupção, que perduram até o presente, em uma nem sempre fácil convivência nacional.

Palavras-chave: Revista História da Educação Latino-americana, história, educação, Argentina, dicotomias. 


\section{INTRODUCCIÓN}

Frecuentemente, en el pasado, se ha pensado al ser humano prescindiendo de su entorno. Contra ese modo de pensar, en gran parte, la influencia del pensamiento hegeliano incidió para que se consideraran los acontecimientos no solo históricamente sino, además, dialécticamente.

Con esta influencia, reforzada, por otra parte, por la impronta dada por Darwin a la importancia del tiempo en la comprensión de la evolución, hoy consideramos más fácilmente la incidencia interactiva de los hombres sobre el medio y de este sobre aquellos.

El modo en que se ha considerado el proceso educativo no ha sido una excepción. La perspectiva histórica y dialéctica nos permite conocer más cabalmente el presente, insertándolo en el pasado y pensándolo en proyección del futuro. Este hecho ha generado, entre otras causas, una mayor responsabilidad por el cuidado no solo de los recursos naturales no renovables sino también por la repercusión de las acciones humanas sobre las generaciones futuras. No se puede negar, por ejemplo, que el lamentable y execrable hecho del holocausto, generado por los nazis, nos ha sensibilizado acerca de la posibilidad de que todo un pueblo, considerado culto, responsable en sus tareas y obediente a sus superiores, ha podido ser involucrado en semejante delito de lesa humanidad, y considerar que ese hecho, tras las promesas seducciones de la política, podría repetirse. ${ }^{3}$

Argentina, de hecho, ha vivido tanto en el siglo XIX, como en el siglo XX, acontecimientos que no pasan como indiferentes y sin incidencia en la forma de pensar la preparación para el ejercicio de la ciudadanía en el proceso educativo.

\section{Los inicios de las propuestas educativas}

Educar, en la tradición occidental, ha significado fundar y definir la propia humanidad, lo que posibilita el desarrollo de lo que las personas y las sociedades deseaban para sí mismas. En estas páginas se desea indicar cómo los intereses sociopolíticos (en especial, los vividos por la clase dirigente), al

3 Cfr. Arendt, Hannah. La promesa de la política, (Barcelona: Paidós, 2008). Arendt, Hannah. Eichmann en Jerusalén, (Barcelona, Lumen, 2003). Todorov Tzvetan. Memoria del mal, tentación del bien, (Barcelona: Península, 2002). 
generar una forma de vida determinada y una opción de valores, han signado históricamente la dirección marcada a las instituciones educativas oficiales. De hecho ellas, con esta finalidad, fueron creando instituciones educativas para pergeñar formas culturales y profesionales de vida.

Si nos referimos a Argentina -y sin desear hacer aquí una erudita y completa historia de la educación argentina, sino encuadrar el tema al indicar el clima de interés o abandono que ha suscitado el problema educativo-, cabe mencionar que, en Córdoba, los jesuitas crearon el primer colegio, el Máximo, en 1613, convertido en universidad en 1634, en la que se impartía Artes (lenguas, lógica, física aristotélica, metafísica) y Teología, universidad renovada por las ideas del Dean Funes en 1813, dispuesto a aprovechar moderadamente "las luces de la edad moderna".

Los eruditos docentes trataron de conciliar las creencias cristianas con las ideas del siglo de las luces, en una forma que no hiciese contradictoria a la fe profesada en relación con las nuevas ciencias. En consecuencia, se advierte una doble vertiente que perdurará hasta el presente en la educación argentina: ya dar primacía valorativa a las creencias religiosas, ya a las experiencias científicas y a los razonamientos basados en ellas. Una tercera vía temporaria consistirá en formar para una vida civil y moral (una moral provisoria sostuvo Descartes), hasta tanto se aclarasen las dos posiciones confrontadas.

En este contexto, ya en el virreinato de Vértiz, tuvo prestigio el real colegio de San Carlos en Buenos Aires (1783). En él fueron profesores Manuel Gregorio Álvarez (1796-1799), quien incluía en sus cursos críticas a Descartes, y aprecio por Gassendi y Newton; ${ }^{4}$ Manuel Suárez de Ledesma, quien apreciaba la filosofía de Francisco Suárez, lo mismo que el profesor Diego E. Zavaleta. Pero desde las invasiones inglesas, el colegio quedó destinado a ser cuartel de tropas. Fue restablecido como Colegio de la Unión del Sud, por Pueyrredón en 1818, introduciéndosele contenidos científicos y haciéndosele apoyar sobre la idea de "vida virtuosa".

Pero la educación, entendida en un sentido amplio como la cultura adquirida y formalizada de un pueblo, tenía un interés prácticamente nulo por parte

4 Cfr. c. lértora de mendoza, La enseñanza de la filosofía en tiempos de la colonia. Análisis de cursos manuscritos. (Buenos Aires: Fundación para la Educación, Ciencia y Cultura, 1979), 46. 
de la población. Esta, en su mayoría, "no sabía leer ni escribir", -según afirmaciones del recién llegado obispo de Córdoba Fray José Antonio en 1780- y advertía que el clero, indisciplinado, no tenía vocación docente. Se hace patente, pues, la diferencia que existía entre la orientación de la elite y su concepción de la cultura, y la vida de la mayoría de los ciudadanos, urgidos por intereses vitales más cotidianos.

La revolución de Mayo de 1810, en Argentina, encontró una ocasión propicia en los acontecimientos europeos. Ella fue una ocasión favorable para comerciantes y militares -y promovida por ellos-, para favorecer principalmente la libertad comercial ${ }^{5}$ requerida por una concepción moderna -y algo romántica, con fantaseados cambios rousseaunianos en hombres como Mariano Moreno, secretario de la primera Junta revolucionaria- del mundo, donde la población masiva estuvo casi ausente. ${ }^{6}$ Este origen parece haber marcado, como un trágico destino, los dos siglos y los dos protagonistas de fondo de la historia argentina: los comerciantes y militares. El "pueblo" -invención moderna- no aparecía aún en el escenario de la historia argentina.

Algunos próceres, tras el ideario de libertad de 1810, como Mariano Moreno y Benardino Rivadavia, criticaron la educación española y jesuita por "no cuidar de instruirse en las ciencias naturales" y por ser "teólogos intolerantes". ${ }^{7}$ Innegablemente estos próceres no consideraban a la educación como aislada de los problemas políticos y sociales de Argentina.

En general, se puede decir que estos patriotas fueron liberales solo en el sentido de que se opusieron al dominio español, al afirmar el derecho a una soberanía nacional (lo que se concreta en 1816) y fueron republicanos y federales con relación a una forma de gobierno opuesta a la monarquía española (lo que se concretó con la Constitución Nacional de 1853).

Manuel Belgrano, según se lee en sus Memorias, ${ }^{8}$ uno de los máximos próceres argentinos, propuso un programa educativo en el que deseaba crear

5 Cfr. R. Bortnik, Historia elemental de los argentinos. (Buenos Aires: Corregidor, 1973): 43. En el cabildo abierto del 25 de mayo de 1810 estaban presentes 60 militares y 49 votaron la destitución del virrey Cisneros. 86 votantes más se plegaron, sin más, al dictamen de Saavedra. Cfr. G. Furlong, La revolución de Mayo. (Buenos Aires: Club de Lectores, 1960): 60.

6 Cfr. F. Pigna, Mariano Moreno. (Bs. As., Emecé, 2009).

7 M. Moreno, Vida y memorias del Dr. Mariano Moreno en Memorias y Autobiografías. (Buenos Aires: Museo Histórico, Nacional, 1910, Tomo II): 20, 18.

8 Cfr. Manuel Belgrano, Memoria. (Consultado 15-10-13 http://www.biblioteca.org.ar/libros/150054.pdf). Manuel Belgrano, Autobiografía (Consultado 15-10-13 http://integrar.bue.edu.ar/wp-content/uploads/2011/05/Manuel-Belgrano.Autobiograf\%C3\%ADa.pdf). 
una escuela gratuita de comercio y otra de agricultura, intentando sacar al pueblo de la ociosidad.

Este prócer encarna en su persona la disyuntiva propuesta, por un lado fue una persona culta, conocedora de las ideas europeas de la ilustración y, por otro, fue una persona profundamente religiosa y moralmente austera. En ese contexto existencial propuso generar escuelas gratuitas para niñas, inspirándoles amor al trabajo, especialmente al hilado y tejido. Reconocía que había escuelas de primeras letras, pero pocas, mal organizadas y sin control. Propuso, pues, por una parte, que se establecieran escuelas en cada parroquia y que los jueces obligaran a los padres a enviar a sus hijos a la escuela y, por otra, que los párrocos inculcaran esto. Lo que indica que si bien el aprecio por el conocimiento escolar formalizado era casi nulo en la población, Belgrano trató de establecer una idea de educación que imbrincara tanto las ideas modernas, tendientes a lo científico e industrial, como las religiosas y tradicionales.

Otros próceres, como Mariano Moreno, fray Francisco de Paula Castañeda, Juan Ignacio Gorriti, temían la dualidad planteada, estimaban que la revolución política no significaba nada si no se la acompañaba con una revolución en la instrucción y educación. Por un lado, ante un pueblo ignorante, cualquier astuto se hacía elegir diputado nacional y llevaba a las asambleas "su presunción, su pedantería, su ignorancia y su corrupción". Por otro, sin un sentido moral y patriótico, se temía a las consecuencias violentas de la Revolución Francesa.

Mas las preocupaciones por la educación formalizada quedaron en buenos deseos, en parte por la ausencia de maestros y en parte porque los problemas políticos no estaban aún resueltos. Aunque a partir de 1913 se fundaron algunas escuelas municipales, las que continuaron funcionando fueron las conventuales, con una didáctica rudimentaria, dado el poco interés docente de los religiosos. Aunque la Asamblea del año XIII suprimió la pena de los azotes, se siguió aplicando por largo tiempo, pues los preceptores protestaban, dado que se les quitaba el único "recurso pedagógico" que tenían. ${ }^{9}$ En un artículo del diario oficial la Gaceta de Buenos Aires, aparecido el 31

9 Cfr. M. Solari, Historia de la educación argentina. (Buenos Aires: Paidós, 1949), 64. A. Salvadores, La instrucción primaria entre 1810 y la sanción de la ley 1420. (Buenos Aires: Consejo Nacional de Educación, 1941). 
de enero de 1821, se afirmaba que la generación siguiente maldeciría a la presente por el abandono en que se hallaba la enseñanza: "Nada hay más atrasado en el día que la educación y en nada se piensa menos".

Belgrano, Moreno y Rivadavia tenían en claro cuán necesario era promover la educación en forma generalizada, como medio para promover el comercio y las ideas de sociales y políticas la Ilustración.

En 1821 se funda la universidad de Buenos Aires, siendo ministro de gobierno Bernardino Rivadavia, lo que significó un avance en este sentido, al preparar hombres no solo para la ciencia sino también para la vida social y política. En 1822 se establece por decreto el método de enseñanza de Lancaster (o de enseñanza mutua, donde los alumnos de grados superiores enseñan a los de los grados inferiores) y con dificultad se aplica este método en el resto del país, subsanándose, en parte, la escasez de maestros. Mas caído el régimen presidencial de Rivadavia, las escuelas quedaron en manos de un Inspector General de Escuelas, el Dr. Saturnino Segurola, quien anuló lentamente las innovaciones iniciadas por Rivadavia.

Don Juan Manuel de Rosas siguió promoviendo un alejamiento de las ideas de la Ilustración, impuestas con un régimen unitario, y fomentó un acercamiento a las ideas federales. Con el primer y segundo gobierno de Juan Manuel de Rosas se da uniformidad a la educación que debía adherir "a la causa federal", separando de las cátedras a quienes no participaban de la forma de gobierno establecida por este. Además, Rosas apelaba a un retorno a las costumbres patrias y a la tradición religiosa católica (considerada religión del Estado), al respecto a las autoridades, gobernando a la provincia de Buenos Aires como si fuese una gran estancia. De hecho, en 1842, colocó a las escuelas de la ciudad bajo la dependencia del jefe de policía. El 27 de abril de 1838 suprimió el sueldo de los educadores, los cuales, en adelante debían exigir a los padres una cuota para mantener los gastos de las escuelas, útiles y sueldos. Los niños pobres quedaron, de hecho, proscritos. ${ }^{10}$

Si la recaudación y mantenimiento de una escuela no era posible, se clausuraba. Rosas, defendiendo la causa federal y reprimiendo toda expresión de ideas contrarias, se creó los enemigos que pensaban al país como una

10 Cfr. Tulio Halperin Donghi, De la revolución de la independencia a la confederación rosista. (Buenos Aires: Paidós, 2000). J. C. Charamonte, Nación y Estado en Iberoamérica. (Buenos Aires: Sudamericana, 2004). 
nación europea, comercial e industrial, con ideales sociales cercanos a los de la Revolución Francesa.

Rosas temía, en efecto, que "la enseñanza libre" introdujera "la anarquía en las ideas de los hombres". Sus opositores, -en especial Domingo F. Sarmiento, refugiado en Valparaíso y admirador de EE. UU., Juan Bautista Alberdi, primero socialista romántico que creía en la educación por las cosas y Esteban Echeverría, ${ }^{11}$ educado en las ideas socialistas vigentes en Francia entre 18251830, aunque crítico de los desórdenes de esa revolución, y refugiado en Montevideo- veían en la libertad el modo de emancipar a las masas y abrir el camino para gestar un ciudadano y una nación soberanos. En modos diversos, estos hombres ven a la educación como agente socializador de las nuevas generaciones y dirigida a inculcar los valores y marcos de referencia de la cultura dominante. ${ }^{12}$

Este ideal, sin embargo, requirió de bastante tiempo para poder expresarse en los hechos. Los colegios de enseñanza privada emitían certificados que eran aceptados por la Universidad de Buenos Aires. En las demás provincias, las escuelas de primeras letras tuvieron, en general, una existencia languideciente y variada, libradas a la suerte. Las escuelas medias tuvieron, en este periodo, alguna presencia en las provincias de Entre Ríos, Salta, Corrientes y Santa Fe. Estas escuelas medias se organizaron con la fundación del Colegio Nacional de Buenos Aires en 1863, a cuyo programa debían acomodarse las demás escuelas de este tipo. En 1869 el congreso nacional sancionó la ley que autoriza la creación de escuelas normales para formar maestros competentes.

Con el establecimiento en Argentina de las constituciones provinciales (entre 1853-1860) se inicia la organización de las escuelas de instrucción primaria. Este hecho no soluciona, sin más, un cambio social propuesto por las ideas de la Ilustración, que suponían no solo una mejora en el comercio, sino una idea moderna del Estado.

La mayor dificultad era cultural: la población tenía una "profunda indiferencia" por la educación formal completa y un "espíritu exclusivamente mercantil". Por ello, después de uno o dos años de escolaridad, el estudiante

11 Cfr. E. Echeverría, Dogma socialista en Obras Completas. (Buenos Aires: Casavalle, 1874. Tomo IV).

12 Cfr. J. Tedesco, Educación y sociedad en la Argentina, 1880-1945. (Buenos Aires: Solar, 1986), 63. D. F. Sarmiento, Obras completas. (Buenos Aires: Luz del Día, 1950, Tomo V) X-XII. 
"pasaba al mostrador de una tienda o de un almacén", según afirmaba Amadeo Jacques. No hubo, en realidad, por mucho tiempo, una demanda masiva de educación superior. La clase alta de la sociedad argentina, constituida por los grandes propietarios, fue, por un siglo, rica y minoritaria, y requería con preferencia un perito en leyes.

Los campos mayores de 5000 hectáreas (en 1914, en la zona de Buenos Aires, Córdoba, Santa Fe, y Entre Ríos) que "representaban cerca del 70\% de las tierras cultivadas, pertenecen a 2447 propietarios". ${ }^{13}$

Aunque la Constitución establecía que cada provincia asegurase la educación primaria de sus provincianos, de hecho el gobierno provincial no se pagaba a los docentes, o lo hacía con subvenciones ocasionales. También en ello estaba presente la corrupción. Sarmiento narra (en el Monitor de la educación común) el caso de una directora de niñas de Santiago del Estero que se negó a firmar el recibo de 130 pesos fuertes cuando recibía solo 65, por ello fue depuesta y separada de la enseñanza por una Junta. ${ }^{14}$

En el nivel nacional e institucional fueron, luego grandes propulsores de la escolaridad, el temperamental ${ }^{15}$ Sarmiento, (promotor de la escuela popular o primaria común y del magisterio, primero en Buenos Aires, después en San Juan, finalmente como presidente) y Nicolás Avellaneda en el siglo XIX, creando éste los colegios secundarios nacionales (luego llamados bachilleratos), en 1864, en diversas provincias, para formar la elite que luego concurriría a las universidades de Córdoba o Buenos Aires.

Sarmiento estaba pensando en una Argentina que se apoyaba económicamente en la ganadería (la cual era pasiva, no daba ni necesitaba mucho trabajo ni mano de obra), y que debía pasar a ser una Nación agricultora e industrializada si deseaba ser una Nación moderna. La obra maestra y poema nacional de José Hernández, el Martín Fierro, describe esta situación. El gaucho o criollo estimaba que la educación dependía del aprendizaje, no

13 J. Hernández Arregui, La formación de la conciencia nacional. (Buenos Aires: Hachea, 1970), 55.

14 F. Hillert, et al. El sistema educativo argentino. Antecedentes, formación y crisis. (Buenos Aires: Cartago, 1985), 106.

15 Cfr. D. F. Sarmiento De la educación popular (1849) en Obras completas. (Buenos Aires: s/e, 1950). Sarmiento, combatiendo a López Jordán, a quien acusaba de haber asesinado a Urquiza creó "el ejército de observación" para vigilar a Entre Ríos. Trajo entonces nuevo armamento a Rosario y -el fundador de escuelas- no dudó en hacerlos probar disparando contra las paredes del colegio nacional. El diario local protestó por el hecho. Cfr. A. Bunkely, Vida de Sarmiento. (Buenos Aires: Eudeba, 1966). C. Ortiz De Montoya, Aspectos pedagógicos de la obra de Sarmiento. Paraná, UNL, 1969. D. F. Sarmiento, Ideas pedagógicas. (Buenos Aires: Talleres del Consejo Nacional de Educación, 1938). 
tanto de las ciencias (como lo entendían cultos los iluministas porteños) sino de una vida moral honesta. Él tenía la tarea de cuidar de la ganadería y pocas letras, pero no carecía de una sabiduría popular labrada sobre la experiencia y la reflexión por medio del sufrimiento, en una sociedad que ya lo comenzaba a verlo como un vago. En las décadas de 1860-1880, el gaucho debió ir convirtiéndose en labrador, reconociendo sus límites.

Yo nunca tuve otra escuela Que una vida desgraciada No estrañen si en la jugada Alguna vez me equivoco Pues debe saber muy poco Aquel que no aprendió nada.
Hay hombres que de su cencia

Tienen la cabeza llena;

Hay sabios de todas menas (clases)

Mas digo, sin ser muy ducho -

Es mejor que aprender mucho

El aprender cosas buenas. ${ }^{1}$

Para lograr el cambio y paso de una economía ganadera a una economía agricultora, era importante poner énfasis en la educación primaria a la que se veía como un motor de civilización: la escuela debía ser laica (mejor dicho, no confesional), pública, con el aporte del Estado y de los padres, común y popular, con un Estado que preside, dirige e inspecciona la enseñanza.

La institución escolar, emergente a fines del siglo XIX, respondería a un modelo social, que “[...] se replicaría en la organización del sistema escolar:

- La determinación de los saberes válidos por imposición,

- el no reconocimiento de los saberes y capacidades de la sociedad para

intervenir en su conducción y en el diseño del currículum,

- la formalización extrema de los comportamientos internos,

- su solemnización y ritualización,

- la inculcación patriótica,

- la disciplina heterónoma,

- la autoridad centralizada en la dirección,

- la uniformidad del perfil cultural en el que se inscribía la formación de los egresados $[\ldots]^{16}$

La autora A. Puigrós califica al sistema educativo de esta época como Sistema de Instrucción Pública Centralizado Estatal, y le atribuye las siguientes características, hegemonía del Estado y subsidiariedad privada; laicismo o

16 Adriana Puiggros, "Modernidad, posmodernidad y educación en América Latina”. En Alba, Alicia (compiladora): Posmodernidad y Educación. (México: Editora Centro de Estudios sobre la Universidad, 1998), 18. 
catolicismo subordinados a la lógica del Estado. Se trató de un sistema escolarizado, verticalizado, centralizado, burocratizado, oligárquico-liberal; no participativo, ritualizado, autoritario. Este sistema discriminó a los sectores populares (hecho que se expresa por medio de la expulsión de los alumnos, la repetición, la no admisión, el desgranamiento y la marginalización de los sujetos sociales que pertenecen a los sectores subordinados $\mathrm{u}$ oprimidos de la sociedad).

Además de estas limitaciones ideológicas observables, en la década de 1880, Argentina tenía una escolarización del 29,50\% de los niños, lo que era un índice muy alto en esa época. ${ }^{17}$ La sanción de la primera ley universitaria (1885) posibilitó la creación de universidades provinciales, antes de finalizar ese siglo, luego se nacionalizaron. ${ }^{18}$

Si bien los acontecimientos históricos marcan una cierta orientación, no obstante, no la determinan. La pujanza de las personas termina imponiendo las necesidades de las personas y su reconocimiento. En este sentido, si bien la educación argentina, en sus inicios, fue marcadamente machista, las mujeres tuvieron un papel importante en la tarea educativa. Juana Manso, ${ }^{19}$ colaboradora de Sarmiento, veía la necesidad de considerar la educación como un proceso integral de formación de la persona, y no descuidó los aspectos psicológicos y sociales de los alumnos y de los docentes.

El hombre que despreciado por sus conciudadanos, oprimido por sinsabores, hostigado por la penuria de los medios, ve sufrir a los suyos sin poder aliviarlos aunque solo sea para hacer más tolerable su posición, trabaja muchas veces diez o doce horas por día, pero ese desgraciado no ama ni puede amar una profesión tan ingrata, y si no la deja, es porque no se le presenta otro recurso; pero la considera su presidio y su cadena; él no puede, aunque quiera, ser amable y paciente con sus discípulos, y la disposición dolorida de su espíritu ha de reflejarse en sus actos en la escuela. ${ }^{20}$

17 C. Bonantini, Educación y sociedad. Análisis histórico estructural de la escuela media argentina. (Rosario: UNR, 1994. Tomo I (1810-1945), 54.

18 Cfr. D. Cano, La educación superior en la Argentina, (Buenos Aires: Centro Editor, 1985), 25.

19 Gabriela Hernández Vega, "Educadora Juana Paula Manso. Precursora del feminismo en el sur del continente americano 18191875". Revista Historia de la Educación Latinoamericana 13, 17 (2011, julio-diciembre): 347-362. Elisabetta Pagliarulo, “Juana Paula Manso (1819-1875). presencia femenina indiscutible en la educación y en la cultura argentina del siglo xix, con proyección. Americana", Revista Historia de la Educación Latinoamericana 13, 17, (2011, julio-diciembre): 17-42. Consultado el 09-10-13. http://www.redalyc.org/src/inicio.

20 M. Solari, Historia de la educación argentina 142. 
Es conocida la preocupación de Sarmiento por traer maestras a Argentina. Ambos, Sarmiento y Avellaneda, veían a la escolarización como una necesidad moderna para una sociedad republicana y productiva. Estratégicamente pensaron entonces en formar a los formadores y a las formadoras, y fundaron las escuelas normales para formar maestras, maestros y profesores.

Resumiendo este período inicial, se puede sostener que los principios constitutivos del sistema educativo de esta época giraron sobre: a) el laicismo (no intervención religiosa, aconfesional en la enseñanza, preferencia por una visión científica de la vida); b) sobre el estatismo (tendencia al monopolio del Estado nacional en materia de docencia pública rentada); c) sobre la centralización de la gestión de servicios educativos en lo administrativo, financiero y pedagógico; d) sobre una concepción enciclopedista como modelo pedagógico, por lo que saber suponía conocer acumulativamente los resultados de las ciencias (no tanto pensar críticamente como implica el método científico).

Este tercer aspecto, no obstante la buena voluntad civilizatoria, generó una concepción pseudo humanista, memorista, vuelta hacia el pasado repitiendo los conocimientos, sin preocupación por la enseñanza técnica, comenzó a ser enseñada como una salida laboral rápida, sin necesidad de desarrollo de la capacidad creativa, crítica, social y política en los alumnos.

\section{La presencia de la visión positivista}

Las dos vertientes que he propuesto como eje de interpretación (la tradicional fundada en una valoración de las creencias morales y tradicionales, y la iluminista en la que la ciencia era el medio superador de las concepciones tradicionales) siguieron marcando el final del XIX e inicios del XX.

La educación argentina ha dependido, en gran manera, de las escuelas normales creadas a finales del XIX. Estas vivieron encapsuladas en un clima de positivismo ahistórico. Se enseñaban las ciencias, como disciplina mental, fuera de todo contexto histórico, político, económico y social $^{21}$. Solo para recordar un aspecto, se puede mencionar que J. Alfredo Ferreyra (1863-1938), Inspector General de Enseñanza Secundaria, fundó en 1895, con Pedro Scalabrini (1849-1916), la revista La Escuela Positiva.

21 Cfr. S. Villavicencio, José Ingenieros y el imaginario positivista de la ciudadanía, en H. Quiroga, y otros. Filosofías de la ciudadanía. (Rosario: Homo Sapiens, 1999), 114. 
Pero este positivismo tenía, por un lado, gérmenes de liberación del pensamiento, por oposición a una aceptación a crítica de las creencias; ${ }^{22}$ más por otro, fue utilizado tras la influencia del darwinismo social de Spencer para categorizar a la educación como adaptación del sujeto al medio en el que vivía, sin cuestionar las orientaciones de ese medio. Los problemas de la educación debían ser considerados como originados en factores biológicos o psicológicos y curados o reprimidos adecuadamente, pero no originados por causas sociales o políticas. ${ }^{23}$

Víctor Mercante (1870-1934) desarrolló luego una pedagogía experimental con presupuestos racistas y elitistas. ${ }^{24}$ Desde el punto de vista didáctico, y entre los docentes escritores de textos de lectura de fines del siglo XIX, cabe nombrar a Pablo Pizzurno (1865-1940) que propuso la idea de que la educación debe ser integral. ${ }^{25}$ Distinguía la educación (tendiente a la formación moral y formación patriótica) de la instrucción (centrada en el conocimiento). En su propuesta incorporó el trabajo como procedimiento regular en huertas, las excursiones, las exhibiciones públicas, la exposición de trabajos e insistió en que la formación debía ser tanto moral como física. En sus textos de lectura utilizó las láminas y fotografías como medios de observación y reflexión para los alumnos.

También José Manuel Eizaguirre ${ }^{26}$ (inspirado como Pizzurno en libros franceses) utilizó dibujos y mapas para ilustrar las ideas de Patria y de formación del ciudadano con sentimientos patrióticos (imponiéndose un cierto ritual militaresco, a iniciativa del Consejo Nacional de Educación, frente a los signos patrios: izar la bandera, cantar el himno nacional, celebración obligatoria de las fechas patrias), frente a la invasión de los inmigrantes. Ambos autores difunden las ideas de liberalismo presente en la Constitución Argentina. Proclaman la libertad y la igualdad de todos los hombres; enseñan una moral no confesional, y racionalmente lustrada, basada en la idea de la formación de un ciudadano

22 "Queríamos nosotros que los alumnos aprendieran a estudiar y a progresar por sí solos. Lo que generalmente se hace es que los alumnos sean recipientes despreciables, incapaces de pensar por sí, de modo que luego salen a fracasar en la vida o a ser esclavos de los déspotas" (C. Vergara, La revolución pacífica. (Bs. As.: Juan Perrotti, 1911), 810. Cfr. C. Vergara, Filosofía de la educación. (Bs. As.: Compañía Sud de Billetes de Banco, 1916).

23 Cfr. Senet, R. Apuntes de pedagogía, adaptados al programa de primer año normal. (Bs. As.: Cabaut y Cía, 1914), 39. A. Puiggrós, (Dir.) Historia de la Educación Argentina. (Buenos Aires, Galerna, 1992). F. Martínez Paz, La Educación Argentina. (Córdoba: Universidad Nacional, 1979), 69.

24 Cfr. V. Mercante, Paidología. Estudio del alumno. (Bs. As.: M. Gleizer, 1927) 301-303. Ch. Hale Ideas políticas y sociales en América Latina, 1870-1930 en Leslie Bethell (ed.) Historia de América Latina, vol. 8, (Cambridge: University Press, 1986). J. Sebrelli, Crítica de las idea argentinas. (Bs. As.: Sudamericana, 2004). r. Cicerchia, Historia de la vida privada en la Argentina, desde la Constitución de 1853 hasta la crisis de 1930. (Buenos Aires: Troquel, 2001).

25 P. Puzzurno, El libro del escolar. (Buenos Aires: Aquelino Fernández, 1901).

26 J. M. Eizaguirre, La Patria. (Buenos Aires: Pedro Igon y Cía, 1894). 
trabajador y honesto. Se cree que no hay desgracia mayor que la ignorancia y no hay defecto mayor que no cumplir con los propios deberes (para consigo mismo, para con los padres, los docentes y la patria). "El que no trabaja y miente no puede considerarse patriota" (P. Pizzurno). Ambos consideran al trabajo como fuente de toda riqueza y felicidad. El ciudadano está protegido por la Ley Constitucional y el Estado protege la libertad de trabajo. Como los fisiócratas franceses estiman que la agricultura es la fuente más fecunda de riqueza e incentivan la idea del valor del trabajo rural. ${ }^{27}$

Los maestros normales, o "normalistas", acentuaron las exigencias del orden, la disciplina y el método, aunque con nulo caudal de crítica social en su saber enciclopédico, gustosos de la acumulación de conocimientos reforzados con la memoria. Augusto Comte (que amaba las matemáticas y que solo pudo cursar dos años en Escuela Politécnica de París, pero no era un científico experimental) hablaba de la ciencia experimental como de algo ya hecho: del mismo modo lo hacían los normalistas.

La ciencia, en lugar de ser un instrumento para liberar el pensamiento, se convirtió, para ellos, en una excusa para suprimir la duda, en la seguridad de poseer la verdad definitiva la cual los habilitaba para enseñar con autoridad dogmática. Habían hecho de la ciencia un sustituto del pensamiento religioso, distorsionando totalmente el sentido de la investigación científica. Al Positivismo le faltó el enfoque epistemológico que le posibilitara distinguir las diversas formas de conocimientos (lógico, social, político, religioso, literario en un contexto histórico), sin necesidad de que una despreciara a las otras.

El Positivismo subordinó las ciencias humanas a las naturales, dio importancia a la libertad individual sin contexto social crítico, al método experimental sin encuadre teórico suficiente, al conocimiento práctico sin la perspectiva de las consecuencias morales.

La razón a-histórica, abstracta, objetivante, parecía haber ganado la contienda sobre la religión y la tradición, pero la victoria había tenido un costo excesivo, suprimiendo el necesario aporte de la subjetividad.

27 Cfr. F. Muscará, “Las ideas pedagógicas de fines del siglo XIX en los libros de lectura”, Educación Cuyo 7 (1998): 165-188. J. Tedesco, Educación y sociedad en la Argentina (1880-1945). (Buenos Aires: Solar, 1986). L. Romero, La Argentina en la escuela. Idea de nación en los textos escolares. (Buenos Aires: Siglo XXI, 2004). 
Casi medio siglo después vendrá, pues, la reacción contra este Positivismo, y la Escuela Nueva caerá en el extremo opuesto del espontaneísmo casi romántico, acentuando la capacidad de sentir lo inefable que reside en el mundo creado. ${ }^{28}$

La dicotomía de valores (vida moral-religiosa o vida ilustrada y laica) en el proceso de educación permanecía, aunque por momentos tomaba matices. La acentuación entre el trabajo acríticamente vivido, por un lado y la solidaridad social, por otro, expresaron también esa dicotomía.

Por una parte, si bien los dirigentes de finales del siglo XIX percibían la importancia del proceso educativo en función de la industrialización del país, con ojos más realistas, advertían, sin embargo, que la economía argentina se fundaba sobre su riqueza agroexportadora, la cual no necesitaba ni mucha mano de obra ni mano de obra especialmente ilustrada.

Por otra parte, la situación de los obreros (clase en creciente aumento sobre todo con el cuantioso ingreso de inmigrantes) era una clase sometida al terrateniente. En este contexto, no faltaron las voces socialistas de los que promovían-como medio de elevación humana-un cultivo de la virtud moral de la solidaridad: las sociedades de socorros mutuos y el trabajo cooperativo. En ellas veían un medio de organización social, humano, democrático y participativo, dando lugar a un verdadero y libre contrato social entre los trabajadores. Estas ideas, surgidas en el siglo XIX, mantuvieron su vigencia, con diverso vigor, durante el siglo XX.

Frente a la cooperación forzada que le impone la dirección capitalista, la clase trabajadora ejercita y desarrolla sus aptitudes para organizar y dirigir por sí sola la producción, practicando en escala creciente la cooperación voluntaria en la acción económica. La cooperación libre es la solidaridad para hacer, y exige de los asociados un grado mucho más alto de capacidad histórica que la acción gremial negativa de las huelgas; es el campo en que los proletarios adquieren derechos y contraen obligaciones entre sí, entre iguales; es para ellos, permanentemente sujetos a la relación extorsiva del salario, la primera ocasión de un verdadero contrato. ${ }^{29}$

28 Cfr. O. Cossettini, Sobre un ensayo de escuela serena en la Provincia de Santa Fe, (Santa Fe: Biblioteca Pedagógica, 1935). Archivo Pedagógico Olga Cossettini. IRICE (Rosario) Material inédito (Carta de Horacio Ratier).

29 Juan Justo, Obras completas. (Buenos Aires: La Vanguardia, 1893, Tomo II), 73. 
En el ámbito educativo, con Carlos Octavio Bunge (1875-1918), la pedagogía trató de encontrar cierta conciliación entre las dos tendencia vigentes. Se debía, pues, tener en cuenta al factor propio (al individuo para percibir las tendencias que sobresalían en él y encausar su profesión) y el factor extraño (o sea, la condición social de la familia para que la enseñanza se adaptase a esa condición, teniendo un sentido práctico que la hacía ética).

Teniendo en cuenta estos factores, Bunge trató de establecer tres leyes fundamentales de la pedagogía, al integrar las exigencias de la subjetividad con las de la objetividad social: a) la ley de la continuidad y gradualidad, al no forzar la naturaleza individual de cada alumno; b) la ley de la universalidad, al tratar de desarrollar todas las facultades en la unidad psicológica del alumno: c) la ley de la especialidad, al posibilitar una formación profesional adecuada a las tendencias y condiciones sociales de cada uno.

El conflicto entre lo racional iluminista y lo afectivo tradicional siguió vigente. El normalismo -sin desconocer que hubo excepciones- estaba marcado, sin embargo, con una herencia racista (la importancia de la raza blanca europea) y antilatinoamericanista, haciendo primar el pensamiento europeo. Acentuaba, además, la importancia del profesor, del especialista o experto (dedicado exclusivamente todo el tiempo y toda su mente a la enseñanza) y no se centraba especialmente en la actividad y el desarrollo integral de los alumnos.

Como reacción al normalismo laicista, las escuelas confesionales de primeras letras acentuaron la docencia de valores morales, pero fuera de un contexto histórico, político, económico, y social, críticos, y encapsulados en una visión descarnadamente metafísica y religiosa. ${ }^{30}$ En general, estas escuelas tomaron una actitud apologética de rechazo de todo lo que significase un pensamiento político no solo de tinte socialista sino también de "desorden liberal". ${ }^{11}$

Mas la religión católica, heredera del orden feudal, tuvo que adecuarse a las nuevas exigencias del mundo liberal. De hecho, sus clérigos defendieron teóricamente la libertad y la teoría de que el origen del poder residía en el

30 Cfr. C. Newland, "La educación elemental en Hispanoamérica: desde la independencia hasta la centralización de los sistemas educativos nacionales", Hispanic American Historial Review 71, 2, (mayo, 1991): 14, M. Bjerg, "Educación y etnicidad en una perspectiva comparada. Los inmigrantes daneses de la pradera y de la pampa, 1860-1930", Estudios Migratorios Latinoamericanos 36 (1997): 7

31 Martínez Paz, La Educación Argentina, 69. Cfr. S. Torrado, Historia de la familia en la Argentina (1870-2000), (Buenos Aires: Ediciones de la Flor, 2003). G. Lipovetsky, Metamorfosis de la cultura liberal. (Barcelona: Anagrama, 2003). E. Todd, La ilusión económica. Sobre el estancamiento de las sociedades desarrolladas. (Buenos Aires: Taurus, 1999). 
pueblo. En Europa, en el pasado, principalmente Guillermo de Ockham y Francisco Suárez y en Argentina del siglo XIX lo hicieron numerosos clérigos representantes de las provincias y firmantes del Acta de declaración de la Independencia Nacional (once sobre los veintinueve presentes).

Los gobernantes del siglo XIX, no obstante que percibieran que la religión tenía una función de contención moral, que cumplir en la sociedad, advirtieron rápidamente que no serían los clérigos los que harían a la grandeza de una nación industrial y comercial moderna que deseaban erigir.

\section{La legislación sobre la educación en el siglo XIX}

En 1878 se aprobó la Ley 934 que reglamentaba la libertad para la enseñanza privada y religiosa, reservándosele a esta un módico espacio. Los institutos privados debían elaborar programas que comprendieran las mismas materias que los colegios nacionales y eran libres para someterse a examen ante los tribunales de estos institutos a fin de obtener oficialmente sus títulos. ${ }^{32}$

En 1883, tiene lugar el primer Censo Nacional Educativo, que arroja un 75\% de analfabetismo. En 1884, se promulgó la Ley 1420 en la que se concebía a la educación con un enfoque nacional y obligatorio. La educación era impartida por el Estado como un "servicio público" y, por lo mismo, gratuito, desde una perspectiva laica y apreciadora del saber científico. Si bien se admitía en la Constitución Nacional que la mayoría de la población argentina era de confesión católica y se sostenía oficialmente este culto, el Estado en sí mismo se consideraba aconfesional o laico. En el artículo $8^{\circ}$ de la Ley 1420 se admitió, sin embargo, la enseñanza religiosa como objeto de materia extracurricular y opcional. "Los liberales se mostraron respetuosos de las creencias religiosas y los católicos de la libertad de conciencia". ${ }^{33}$

En 1885, por medio de la denominada "Ley Avellaneda", se concede la autonomía universitaria para las casas de altos estudios de Córdoba y Buenos Aires. Entre el 1916 y 1921 los colegios privados pasaron de ser el 41\% de los establecimientos educativos, a ser el $32,6 \%$.

\footnotetext{
32 El obispo de Córdoba, monseñor Clara, negó, en una carta pastoral, facultades al gobierno para intervenir en materia de enseñanza. El presidente Roca lo destituyó y lo sometió a la justicia federal. Se interrumpieron las relaciones con el Vaticano.

33 Hillert, et al. El sistema educativo argentino, 123. El artículo $8^{\circ}$ fue derogado en 1920 y vuelto a establecer, por decreto, en 1943 , haciéndose obligatoria la clase de religión o moral. En 1955, por la ley 14401 se suprimió la enseñanza religiosa en Argentina.
} 
En un sentido muy diverso, Carlos N. Vergara, por medio del Krausismo, rescató el aspecto socialista y humanitario que yacía en el positivismo, ${ }^{34}$ proponiendo a la educación como promotora del espíritu republicano democrático, respetuosa de los pobres, los débiles y humildes. “Casi todos los que están en las cárceles son analfabetos, irresponsables, víctimas de los malos ejemplos de los de arriba. En tanto los altos funcionarios que corrompen al país permanecen inmunes. Sin esos grandes criminales, los hoy presos estarían inmunes" ${ }^{35}$

Vergara reconocía que el alma española nos legó sus vicios (soberbia, prepotencia, picardía), pero también sus virtudes (amor a la tierra, valor, inteligencia, el deseo de autonomía). No temía a las inmigraciones, sino que veía en ellas la posibilidad del surgimiento de un sujeto de educación más complejo y enriquecido. Para él las masas no eran necesariamente buenas (como pretendían los anarquistas) ni necesariamente malas (como para los positivistas latinoamericanos) sino que el ambiente social y la educación podían estimular tanto vicios como virtudes.

Con la generación de los "normalistas" y el Congreso Pedagógico (1882) se impusola educación oficial como no confesional o laica, y se percibióla influencia del pensamiento de Pestalozzi. En 1891, el presidente Carlos Pellegrini crea la primera escuela nacional de comercio (ya deseada por Belgrano), y en 1917 se crean las escuelas de artes y oficios para promover la industria.

El intento de reforma educativa del Ministro de Instrucción Pública, Saavedra Lamas, en 1916 -que reducía la escuela primaria gratuita y obligatoria a cuatro años (de ocho a doce años), siguiéndole luego un ciclo intermedio que preparaba para el comercio, la industria y la universidad a la cual todo debía tender-, fracasó, siendo rechazada por los diputados socialistas y radicales, por tender a crear dos clases sociales, según ellos: la popular para el trabajo y la elitista para formar dirigentes. ${ }^{36}$

Es importante recordar que hacia el 1914 la mayoría de la población argentina estaba marginada del sistema educativo. Un $11 \%$ estaba escolarizado.

34 Recuérdese la idea de Augusto Comte de sustituir todas las religiones por la religión de la Humanidad. Cfr. A. Comte, Catecismo positivista en La Filosofía Positiva. (México: Porrúa, 1979) 115. Comte concebía al hombre con "un carácter profundamente egoísta que solo la transformación gradual producida por la marcha colectiva puede hacer altruista” (211).

35 Vergara, La revolución pacífica, 613. Cfr. Puiggrós, Sujetos, disciplina y curriculum, 193.

36 Cfr. Saavedra Lamas, Reformas orgánicas de la enseñanza pública: sus antecedentes y fundamentos, (Buenos Aires: Peuser, 1916). Juan Carlos Tedesco, Educación y sociedad en la Argentina, (1880-1945). (Buenos Aires, Solar, 1986). E. Mayochi, et al. Fundamentos constitucionales del sistema educativo. (Buenos Aires: Estrada, 1969). 
El segmento universitario era del 0,11\% (unos 8500 alumnos sobre una población de ocho millones).

"Socialistas y radicales se acercaban más al problema al centrar como eje prioritario de la acción educativa la erradicación del analfabetismo, ya que en ese momento este era muy alto, alcanzando el $35 \%$. Cabe recordar que hacia 1895 el analfabetismo era del 54,4\%". ${ }^{37}$

\section{La presencia estudiantil universitaria}

Desde la Ley Avellaneda 1885 hasta 1918 existieron tres universidades nacionales: las de Córdoba, Buenos Aires y La Plata, con una matrícula relativamente escasa, con profesores con prestigio personal, magistrados y políticos bien remunerados. Los docentes repetían los conocimientos en el mejor estilo enciclopedista, sin investigación propia ni participación de los alumnos, con consejos académicos vitalicios o hereditarios.

Mas ante una sociedad conservadora, los mismos estudiantes propulsaron una reforma universitaria con mayor autonomía, como "entidades dotadas de vida propia". La revuelta estudiantil realizada en Córdoba (15 de junio de 1918), impulsada por el joven abogado Deodoro Roca, quien redactó un documento como una neta reacción antiimperialista, anticlerical, antimilitar y contra los gobiernos oligárquicos. Se proponía una reforma que implicaba la autonomía universitaria respecto de los gobiernos de turno; un gobierno universitario tripartito (profesores, graduados, y estudiantes); cátedras obtenidas con concursos públicos, periódicos y de oposición, con cátedras paralelas; con centros de estudiantes por facultades, elegidos democráticamente; con ingreso irrestricto; con investigación científica en la universidad y con extensión social del conocimiento producido.

Esta propuesta de reforma tuvo de hecho una repercusión en toda América Latina y significó la reforma de una universidad cerrada en sí misma, solo profesional y utilitaria. La "reforma" no llegó a concretarse en una nueva ley, pero sí en nuevos Estatutos Universitarios. Se propuso, entonces, la participación de los estudiantes, la libertad de cátedra, la necesidad de la investigación científica en la universidad, la periodicidad de los académicos, su designación con la

37 C. Bonantini, Educación y sociedad. Análisis histórico estructural de la escuela media argentina. (Rosario: UNR, 1994. Tomo I), 105. 
intervención del cuerpo de profesores y la autonomía también en la gestión, aunque no se llegó a replantear el modelo económico vigente.

Las escuelas de Artes y Oficios, creadas en 1917, en 1930 llegan a ser 40 establecimientos de este tipo en la República. ${ }^{38}$ En 1918, solo el 1\% (cerca de 10000) de los estudiantes argentinos era un universitario de las únicas tres universidades nacionales existentes, siendo la mayoría estudiantes de Derecho o Medicina.

En la primera parte del siglo XX, la historia de la educación en Argentina, además de generar la autonomía universitaria en la educación superior, padeció luego en los niveles inferiores de escolaridad, los avatares de la así llamada escuela nueva o activa, con dos vertientes: o bien, con una acentuación por lo afectivo y creativo; o bien, con una visión pragmática o recreativa. En ambos casos, no se mejoró la necesidad de ofrecer un aprendizaje en un contexto social, histórico y políticamente crítico. Tanto las escuelas normales, aún en su vertiente humanista, como las escuelas técnicas o de artes y oficios, carecieron de una visión social: se juzgó que era posible educar al individuo; pero no en una sociedad y para una sociedad criticable en un contexto histórico. Se educó para vivir, no para convivir.

En general, la educación era objeto de un discurso que raramente descendía hasta las sugerencias didácticas sistematizadas e institucionalizadas, aunque hubo unas pocas y notables excepciones. La instrumentalización didáctica no fue una preocupación primordial en la historia de la educación argentina. Solo en 1927 se crea el Instituto de Didáctica en la Facultad de Filosofía y Letras de Buenos Aires y el profesorado de Pedagogía en 1936 (suprimido en 1948), generándose luego los profesorados de Filosofía y Pedagogía.

\section{Vientos de dictadura militar}

El infausto derrocamiento militar (por parte del general Uriburu, apoyado por coroneles como Álvaro Alzogaray y por capitanes como Juan Domingo Perón) ${ }^{39}$ del presidente Irigoyen, y los avatares políticos de Europa (la cual

38 Cfr. José Antonio, Sánchez Román, De las escuelas de artes y oficios a la Universidad obrera nacional: Estado, elites y educación técnica en Argentina, 1914-1955. (Consultado en 03-10-13 http://e-revistas.uc3m.es/index.php/CIAN/article/view/1178)

39 A. Castello, Historia contemporánea de los argentinos. Tomo I: La reacción conservadora. (Buenos Aires: Ábaco, 1987), 40. Perón, however, acknowledged in the speech of April 8, 1953, which Irigoyen was "the only president who sacrificed and defended his people" 
se debatía entre el comunismo ruso, el racismo nazi y el fascismo italiano), relevó también de sus cargos a los docentes con opiniones diversas a la oficial. Se elevan los aranceles para el estudio universitario, "para que la cultura no esté en peligro de aplebeyamiento", según una expresión típicamente conservadora de esta época. ${ }^{40}$ Siguiendo una larga tradición, algunos grupos elitistas (que aprovechan los problemas de país, para sacar ventajas propias) influyeron reiteradamente en la historia argentina para inducir a los militares para que ellos se creyeran ser la solución política.

La Corte Suprema de Justicia dio lugar a la tesis de la validez de los poderes de facto. Los centros de estudiantes de la facultad de Medicina y Derecho que habían participado en los hechos políticos, solicitand o un cambio de gobierno, pero sin intervención militar, (“Dictaduras militares no, democracia sí!”) fueron disueltos, durante la dictadura de Uriburu.

En 1939, los docentes de varias provincias, en especial en Corrientes, entran en huelga porque se les adeuda 38 meses de sueldo.

Increíblemente, Padilla, el ministro de educación, suprimió profesorados de formación docente "por exceso de maestros", mientras la tasa de analfabetismo alcanzaba a más del $24 \%$ de la población. En 1943, los maestros trataron de unificar las organizaciones que los asociaba. Mas el golpe militar de ese año acentuó la idea de que la universidad debía formar auténticas aristocracias de la inteligencia que "consagrasen la idoneidad y la responsabilidad de la función política" y el dos de noviembre se intervino a las universidades.

Como se advierte, el país y el modelo de país fue transitando en Argentina y lo seguirá haciendo, hasta el siglo XXI, por vías dicotómicas: educación con valores predominantemente unitarios o bien federales, educación popular o educación elitista; educación para las letras o para el trabajo, educación religiosa o bien laica, libre o estatal, educación patriota (ante la invasión de inmigrantes) ${ }^{41} \mathrm{y}$ militar (como si la historia fuese hecha solo por los militares); educación para la industria o educación para la universidad; educación para valores modernos o en un clima irreversiblemente posmoderno.

40 Ibid.

41 Cfr. F. Devoto, Historia de la Inmigración en la Argentina. (Buenos Aires: Sudamericana, 2004). 


\section{Un proyecto de país que tienda al desarrollo industrial}

Si en la década de 1880 se hizo patente un modelo de país que sostenía un ideal de escuela que posibilitara el ascenso del nivel social de los ciudadanos por medio de la preparación para ocupar cargos en la creciente burocracia estatal o comercial, en la década de 1940 (aunque ya insinuada en la década anterior), se manifiesta otro modelo o más bien proyecto de país. ${ }^{42}$ Se percibe, en los niveles políticos, la necesidad de un proyecto de país que tienda al desarrollo industrial. En este contexto, la escolarización era un bien preciado. Se hicieron nuevos edificios escolares, se duplicó la matricula de la escuela secundaria y se triplicó en la universitaria.

En 1948 se creó la Universidad Obrera Nacional (luego convertida en la Universidad Tecnológica Nacional), destinada a formar ingenieros de fábricas. En ese mismo año, se organizaron las escuelas industriales. Desde el Ministerio de Educación se propició la conciencia y la actividad política o más bien partidaria de los estudiantes (UES: Unión de Estudiantes Secundarios), y de los docentes agremiados (ADA: Asociación de Docentes Argentinos). ${ }^{43}$

Tras el golpe militar, el decreto-ley 6403 de 1955 dejaba abierta a la iniciativa privada la posibilidad de crear universidades en el artículo $\mathrm{n}^{\circ} 28$ que no fue reglamentado. Restablecido el orden constitucional, desde 1958, bajo la idea de una política de investigación y desarrollo, se creó el CONET (Consejo Nacional de Educación Técnica) el INTI (Instituto Nacional de Tecnología Industrial) y el CONICET (Consejo Nacional de Investigaciones Científicas y Técnicas). Por otra parte, se incrementó el servicio nacional de enseñanza privada y en 1958 se redactó y fue aprobada por las cámaras la reglamentación del artículo $\mathrm{n}^{\mathrm{o}} 28$, creándose las universidades de gestión privada (ley 14457), a las que no se les reconoció ninguna forma posible de subsidio estatal. La Iglesia Católica, desde la década del treinta, fue tomando marcada presencia para tener presencia con las escuelas de gestión privada. Se buscaba una ley de enseñanza oficialmente válida, pero de gestión privada. En 1958, en el gobierno de Frondizi, la confrontación popular se presentó como dicotómica: universidad libre o universidad laica; educación

42 Cfr C. Bonantini, Educación y sociedad. Análisis histórico estructural de la escuela media argentina. (Rosario, UNR, 1994. Tomo I-II).

43 Cfr. Segundo Plan Quinquenal de La Nación. Ley no 14.184. (Buenos Aires: Hechos e Ideas, 1954). 
ciudadana pluralista o monopolio del Estado en materia de educación pública (para que no se vuelva "eclesiástica"); libertad de enseñanza (como diversas formas de pensar) o monopolio del Estado (para que todos tuviesen educación aunque no la pudiesen pagar). De hecho, en 1982, ya eran 22 las universidades de gestión privada.

La situación económica general y de los docentes fue delicada. Roberto Áleman, en su breve gestión de tres semanas como ministro de economía, produjo una devaluación del $60 \%$, lo que generó un malestar general. Los sueldos se pagaban con creciente retraso y se llegó a adeudar doce meses de sueldo a los docentes. ${ }^{44}$

\section{Nuevamente la presencia militar}

Desde 1966 a 1973 quedó suprimido el Ministerio de Educación y fue reducido a una secretaría dependiente del Ministerio del Interior. Se implantó la represión de los estudiantes secundarios que solicitaban un pasaje de transporte más adecuado a los humildes (La noche de los bastones largos) y de la libertad de cátedra. Se modificó la Ley y se hizo posible la prescindibilidad de los docentes sin sumario previo; se intervinieron las universidades nacionales y se tendió a favorecer la creación de carreras cortas que preparasen para el mundo tecnológico. En 1971, se suprimieron las escuelas normales que ofrecían el título de Maestro Normal Nacional como una terminalidad (en dos años) del ciclo de la escuela secundaria. La formación de docentes para la escuela primaria pasó a depender de los Institutos de nivel Terciarios de Formación docente.

En el breve período 1973-1975, se intentó crear una participación popular democrática. Se estableció la asignatura ERSA (Estudio de la realidad social argentina) y se creó la CTERA(Confederación de Trabajadores de la Educación de la República Argentina). Socialmente se hizo patente la fractura (iniciada una década antes) entre dos visiones de la sociedad política y económica: la concepción tercermundista con una perspectiva socialista y latinoamericanista, por un lado y, por otro, la nacionalista militar con una perspectiva que apreciaba el liberalismo y la dependencia de capitales extranjeros. ${ }^{45}$

44 Cfr. J. Sebrelli, Crítica de las idea argentinas, (Buenos Aires: Sudamericana, 2004). m. Cavarozzi, Autoritarismo y democracia (1955-1996), (Buenos Aires: Ariel, 1997). M. Navarro, El derrumbe político, (Buenos Aires: Norma, 2002).

45 Cfr. C. García Martínez, El genocidio económico argentino (1975-1989), (Buenos Aires: Macchi, 2003). Luis A. Romero, Sociedad 
Esta fractura llevó a una lucha interior y a la posterior dictadura militar, hasta 1983, que ensangrentó a Argentina (con secuestros, guerrillas, con estudiantes, sindicalistas y militantes desaparecidos, intervención de las universidades y supresión de la libertad de cátedra), terminando con la desacreditación de la fuerza militar tras su derrota en Malvinas. ${ }^{46}$ Desde 1930, el ejército se desubicó y asumió la tarea de ser el garante de la ciudadanía, al margen de los gobiernos democráticamente elegidos. En la década de 1960 creció la guerrilla inspirada en Cuba y en sus secuelas, y también la contrainsurgencia: los militares aprendieron en Panamá a empujar al Estado a la acción clandestina. Matar al enemigo era la forma de construir la nación. ${ }^{47}$

No se trató de un fenómeno solamente argentino sino que varios países latinoamericanos padecieron análogos procesos de ruptura del régimen democrático y desconocimiento de las constituciones nacionales. En este período, la dictadura militar consideró que la educación había sido un lugar especialmente apto para la subversión armada e impuso el control y la represión de las ideas que no concordaban con su forma de ver. ${ }^{48}$ La intervención militar instaló, además, la idea de que el mercado libre debía disciplinar la sociedad. La solución era la apertura de la economía y la reducción de la intervención del Estado en economía. De hecho, se constituyeron los grandes grupos económicos y exprimieron al Estado. Se profundizó la decadencia del Estado y la corrupción de las instituciones.

De modo que a aquellas prácticas de terrorismo de Estado se agregó una segunda cadena de complicidades, que se hundió en lo profundo de la sociedad y llegó a convertirse en hábito aceptado; dejó una herencia de funcionarios, policias y jueces corruptos y acostumbrados a vivir en la corrupción, y una pobre idea del respeto por la ley, siempre subordinada a otras necesidades prácticas. ${ }^{49}$

La juventud abandonó los ideales y utopías de la modernidad y se aferró a la posmodernidad: se centró en el presente, descuidando la lectura del pasado

\footnotetext{
democrática y política democrática en la Argentina del siglo XX, (Buenos Aires: Universidad de Quilmes, 2004).

46 Cfr. M. Bonaudo, Nueva historia argentina, (Buenos Aires: Sudamericana, 1999-2003, Vol. I-IX). M. Navarro, V. Palermo, La dictadura militar, 1976-1983, (Buenos Aires, Paidós, 2003). Sebrelli, J. Crítica de las ideas políticas argentinas, (Bs. As.: Sudamericana, 2004). Martini, L. El encantamiento político. De revolucionarios de los 70 a rebeldes sociales de hoy (Buenos Aires: Ediciones Continente, 2004). N. García Canclini, Latinoamericanos buscando lugar en este siglo, (Buenos Aires: Paidós, 2002).

47 A. L. Romero, La crisis argentina. Una mirada al siglo XX, (Buenos Aires: Siglo XXI; 2003), 68.

48 Cfr. R. Barboza, y otros. Educación y cultura adolescente. Desafío del siglo XXI, (Buenos Aires: Academia Nacional de Educación, 2003 ), 14.

49 A. L. Romero, La crisis argentina. Una mirada al siglo XX, (Buenos Aires: Siglo XXI, 2003), 83.
} 
y la perspectiva del futuro. La imaginación se alejó de los intentos de poder y surgió una generación de "pequeños amores", 50 vividos en el minuto, rápidamente y pidiendo más, en un desconcierto moral, que dará inicio a una corrupción generalizada. ${ }^{51}$

Estudiosos de la historia de la educación en Argentina y en América Latina perciben analogías, que marcaron un siglo, entre la forma de ser social y la forma de organización escolar. Podremos estar o no de acuerdo con la concepción de la sociedad en ese periodo, pero los medios elegidos lograban los fines propuestos.

En el lapso que abarca desde 1880 hasta aproximadamente 1980, el modelo educativo dominante que llamaremos sistema de instrucción pública centralizado estatal (SIPCE) tenía en esa región las siguientes características:

. Hegemonía del Estado y subsidiariedad privada.

. Laicismo o catolicismo subordinados a la lógica del Estado.

. Escolarizado.

. Verticalizado.

. Centralizado.

. Burocratizado.

. Oligárquico-liberal.

. No participativo.

. Ritualizado.

. Autoritario.

. Discrimina a los sectores populares (hecho que se expresa a través de la expulsión, la repetición, la no admisión, el desgranamiento y la marginación de los sujetos sociales que pertenecen a los sectores subordinados u oprimidos de la sociedad).52

Las universidades argentinas comenzaron a expedir títulos que habilitaban para nuevas profesiones (como ingeniería) a fines del siglo XIX, títulos que ya no satisfacían solo las necesidades de la sociedad civil sino tampoco a los de la producción y del mercado. ${ }^{53}$

50 Cfr. M. Fuingeret, (Comp.). Jóvenes en los 90: La imaginación lejos del poder, (Buenos Aires: Almagesto, 1993). M. Margulis, La juventud no es más que una palabra: Ensayos sobre cultura y juventud, (Buenos Aires: Biblos, 1996).

51 Cfr. Z. Bauman, Ética posmoderna, (Buenos Aires: S. XXI, 2004).

52 A. Puiggrós, Sujetos, disciplina y curriculum en los orígenes del sistema educativo argentino (1885-1916), (Buenos Aires: Galerna, 1996). 17. Cfr. j. Tedesco, Educación y Sociedad en Argentina (1880-1945), (Buenos Aires: Solar, 1970). A. Ascolani, (Comp.) La Educación en la Argentina, (Rosario, Estudios de Historia, 1999). L. Bertoni, Soldados, gimnastas y escolares. La escuela y la formación de la nacionalidad a fines del siglo XIX en Boletín del Instituto Ravignani, 13, 1996. D. Rock, La Argentina autoritaria. Los nacionalistas, su historia y su influencia en la vida pública. (Buenos Aires: Ariel, 1993).

53 Cfr. T. Durán Ramos, Globalización y formación profesional: ¿Nuevas reglas? en Educación. Revista de la Universidad de Costa 
En el siglo XX la universidad asumió tres funciones principales: a) preparar profesionales capaces de perfeccionar la propia profesión (y no repetir solamente lo aprendido como lo harán los profesorados); b) generar investigación y c) extender lo logrado en la universidad a la sociedad. ${ }^{54}$

\section{La ley federal de educación}

Hacia el final del siglo XX, las dicotomías iniciales proseguían. En 1984, en la gestión del radical Francisco Delich, se arancelaron los posgrados "porque constituían una inversión individual, privada que reportaría beneficios individuales, privados. En otros términos, reconocíamos la lógica del costobeneficio en el cuarto nivel de la enseñanza superior". ${ }^{55}$

El argumento no podía ser más cínico: ¿Acaso los otros niveles de enseñanza no reportan beneficios individuales y no están regidos por la misma lógica? En realidad, lo que sucedía era que se consideraba a la educación como un gasto y no como una inversión social que beneficiaba a los individuos por igual y a la sociedad. El Estado no quería invertir en calidad. Los gobernantes, creados ellos en la Universidad, cerraban el paso a los niveles de especialización, a las generaciones futuras de la clase media. ${ }^{56}$

En 1985, se realiza el Congreso Federal de Educación, donde los establecimientos confesionales asumieron el protagonismo, y quedó ya claro que la educación podía ser tanto de gestión estatal como de gestión privada (con supervisión estatal, de acuerdo con las normas legales).

En 1993 se aprueba la ley federal de educación $n^{\circ}$ 24195, para regular el derecho constitucional de enseñar y aprender, y tratar de superar las tradicionales dicotomías. Se considera a la educación como "bien social y responsabilidad común" (Art. $1^{\circ}$ ); siendo el Estado el principal responsable de fijar y controlas la política educativa para "formar una sociedad argentina

Rica, 26, 2, (2002): 107-117.

54 Cfr. Torrado, S. Estructura social de la Argentina: 1945-1983, (Buenos Aires: De la Flor, 1994). E. Tenti Fanfani, (Comp.) El rendimiento escolar en la Argentina, (Buenos Aires: Losada, 2002). A. Narozini, et al. El rendimiento escolar en la Argentina, (Buenos Aires: Losada, 2002).

55 F. Delich, La crisis en la crisis. Estado, Nación, Sociedad y Mercados en la Argentina contemporánea. (Buenos Aires: Eudeba, 2002),112. Pablo Pineau, Sindicatos, Estado y Educación Técnica (1936-1968), Biblioteca Política Argentina, (Buenos Aires: Centro Editor de América Latina, 1991). Adriana Puiggrós, Escuela, Democracia y Orden, Historia de la Educación Argentina, (Buenos Aires: Editorial Galerna, 1992. Tomo III). Adriana Puiggrós, ¿Qué pasó en la Educación Argentina? Desde la Conquista hasta el Menemismo, (Buenos Aires, Kapelusz, 1996).

56 Cfr. R. Herrera, “La tecnociencia y la educación: la problemática de su integración”, Revista de Filosofía de la Universidad de Costa Rica, XLVII, 120-121, (2009): 9-17. 
justa y autónoma", integrada al continente y al mundo (Art. $2^{\mathrm{a}}$ ); garantizando el acceso a todos los niveles educativos (Art. $3^{\mathrm{a}}$ ). Se propone garantizar la igualdad en la calidad educativa (Art. 15) y crear, si es necesario para esto, planes asistenciales específicos, "para familias con necesidades básicas insatisfechas" (Art. 40). Finalmente cabe destacar que se establece claramente la finalidad y los valores buscados en la educación del sistema educativo nacional argentino, posibilitando que los ciudadanos

\begin{abstract}
"se realicen como personas en las dimensiones cultural, social, estética, ética y religiosa, acorde con sus capacidades, guiados por los valores de vida, libertad, bien, verdad, paz, solidaridad, tolerancia, igualdad y justicia. Capaces de elaborar, por decisión existencial, su propio proyecto de vida. Ciudadanos responsables, protagonistas críticos, creadores y transformadores de la sociedad, por medio del amor, el conocimiento y el trabajo. Defensores de las instituciones democráticas y del medio ambiente". (Art. $\left.6^{\circ}\right)$.
\end{abstract}

Se establecen entonces los siguientes niveles o grados de educación: inicial, general básica, polimodal, superior (no universitario y universitario) y cuaternario. Quedó integrada también la enseñanza de gestión privada. Se estableció expresamente que el Estado nacional se obligaba a garantizar el principio de gratuidad en los servicios estatales en todos los niveles y regímenes de educación (Art. 39). Se estableció también el Consejo Federal de Cultura y Educación y sus funciones. Las universidades permanecieron en el ámbito de la supervisión nacional y los demás niveles pasaron a depender de las administraciones provinciales. La ley de educación superior ( $\left.n^{\circ} 24521\right)$ reguló la educación superior universitaria y no universitaria, y abrió el camino para generar instituciones universitarias provinciales, como existieron en el inicio de nuestra historia.

Pero otra dicotomía aflora aún: ¿priorizar el conocimiento universalizador o el práctico y aplicado? Las universidades han preferido ofrecer carreras cortas, prometiendo una rápida salida laboral; pero lo inmediato no suele dejar ver lo importante: crear una formación general básica amplia. Se le solicitó al adolescente que en el período polimodal (de la adolescencia temprana: 16-18 años) ya decidiera lo que va a hacer profesionalmente en su vida. Fácilmente se advierte que, en la sociedad posmoderna, con cambios acelerados e intereses cambiantes, se estaba solicitando un imposible. 
El transcurrir del tiempo hace ver que es preferible una formación general más amplia que permita, luego, una formación profesional especializada cuando se ha logrado una madurez psicológica mayor. Una formación general amplia, da las herramientas para generar una compresión de lo humano, por lo que es tan importante como aprender computación como aprender historia (que se pretende suprimir).

Para solucionar esta dificultad, las universidades tendieron a generar un curso básico común para sus carreras y luego una terminalidad específica, dejándose la especialización para el cursado de posgrado (cursos de especialización, maestrías, doctorados), bajo la supervisión de la CONEAU (Consejo nacional de evaluación y acreditación universitaria).

Sin embargo, la situación económica desastrosa que ha padecido Argentina, en gran parte, por la mala gestión de sus dirigentes, por casi un siglo, hace que la situación educativa siga en terapia también en el siglo XXI. La situación económica repercutió duramente sobre la familia argentina. Sobre 36 millones de habitantes, más de 960000 personas nunca fueron a la escuela; otros 3695830 no terminaron la primaria, según surge del último censo del Instituto de Estadística y Censos (Indec). ${ }^{57}$ La creciente falta de exigencia y calidad en la educación formal, iniciaba, también, el "analfabetismo académico", es decir, el de aquellos ingresantes en la Universidad que no pueden comprender lo que leen, expresarse, argumentar o entender una consigna.

La educación no se agota en enseñar a leer, escribir y calcular. Esto a penas alcanza para preparar a una persona a fin de que pueda seguir estando en el sistema educativo, para que adquiera confianza en sus saberes, conciencia de sus derechos individuales y sociales, manejo de la tecnología y una serie de habilidades y sensibilidades para tomar decisiones de manera autónoma, en sociedades como las actuales.

Cuando terminan el secundario, los jóvenes tienen tal déficit en lectura comprensiva y en escritura correcta y en el dominio de las matemáticas que no se puede decir que estén totalmente alfabetizados. La competencia en matemáticas se considera parte principal de la preparación educativa puesto que algunas ideas y conceptos matemáticos son herramientas para actuar sobre la realidad

57 Cfr. La Nación. Consultado on line. el lunes 9 de agosto de 2004. 
Además, en las escuelas primarias, los maestros se sienten impotentes para compensar, en algunas horas de clase, los efectos de la nutrición deficiente, de familias golpeadas por la desocupación y en riesgo social. El sistema educativo no actúa en el vacío, sino en medio de condicionamientos sociales y culturales, pero tampoco se prepara a los docentes para trabajar en contextos de extrema pobreza.

Todo parece indicar que una ley de educación debe ser pensada y revisada periódicamente, para que sea abarcativa de las necesidades nacionales, para que sea federal, capacitadora de los intereses de los ciudadanos. La educación es tan importante que no debe quedar ni en las solas manos privadas, ni en las solas manos del gobierno de turno. Se trata de coordinar esfuerzos y pensar en el bien común de los ciudadanos, en sus derechos y deberes.

Sigue siendo una prioridad para cualquier sociedad que aprecia un régimen político democrático preparar y mantener las condiciones intelectuales y morales que lo hacen posible. Ya Aristóteles afirmaba que no eran las leyes, sino las tradiciones o costumbres democráticas -sobre todo el respeto del derecho de elegir y decidir -las que sostienen la vida democrática. ${ }^{58} \mathrm{Y}$ es que ya el aula debe ser pensada como una sociedad para el aprendizaje, en un clima democrático de intercambio de razones y conductas adecuadas para aprender (con valores subyacentes como el aprecio por el esfuerzo, el respeto mutuo, la aceptación de las diferencias en un clima no de corrupción, sino de la verdad y la justicia). Los sucesos de la historia vivida por los argentinos, con tantas dicotomías y avatares, han terminado finalmente favoreciendo una clima que puede ser propicio para fortalecer la vida democrática presente y futura, sin suprimir la cultura nacional y criolla.

\section{CONCLUSIÓN}

Es sabido que el Programa para la Evaluación Internacional de Alumnos de la OCDE (PISA, por sus siglas en inglés) tiene por objeto evaluar hasta qué punto los alumnos cercanos al final de la educación obligatoria han adquirido algunos de los conocimientos y habilidades necesarios para la participación

58 Cfr. Julián Gallego, Aristóteles, la ciudad-estado y la Asamblea democrática lecciones en tomo al libro III de la Política disponible en: http://revistas.ucm.es/index.php/GERI/article/download/GERI9696110143A/14452 
plena en la sociedad del saber. PISA saca a relucir aquellos países que han alcanzado un buen rendimiento $y$, al mismo tiempo, un reparto equitativo de oportunidades de aprendizaje, ayudando así a establecer metas ambiciosas para otros países.

Las pruebas de PISA son aplicadas cada tres años. Examinan el rendimiento de alumnos de 15 años en áreas temáticas clave y estudian igualmente una gama amplia de resultados educativos, entre los que se encuentran: la motivación de los alumnos por aprender, la concepción que éstos tienen sobre sí mismos y sus estrategias de aprendizaje. Cada una de las tres evaluaciones pasadas de PISA se centró en un área temática concreta: la lectura (en 2000), las matemáticas (en 2003) y las ciencias (en 2006); siendo la resolución de problemas un área temática especial en PISA 2003.

El programa está llevando a cabo una segunda fase de evaluaciones en el 2009 (lectura), 2012 (matemáticas) y 2015 (ciencias). ${ }^{59}$

Argentina ha accedido a esta forma de evaluación internacional y lo que se advierte es que no resulta suficiente aumentar la ayuda económica hasta más de 6\% del PBI para que las escuelas (en este caso las secundarias) generen mejores resultados satisfactorios en el proceso de aprendizaje. Argentina se ha ubicado en el puesto 59 de los 65 países que se sometieron a la prueba PISA, aplicada en el 2012 a las matemáticas. Esto significa que los estudiantes argentinos tienen la misma (in)capacidad para resolver problemas que tenían hace veinte años. No obstante, los avances tecnológicos, la dificultad para las matemáticas siguen siendo la misma, y sigue marcada por un aprecio de los estudiantes por los saberes sociales y no por los formales. Los intereses foráneos no pueden implantarse con decretos de los gobernantes, ignorando los intereses nacionalmente vividos en el interior de la nación. Argentina, mediante los caudillos federales ha optado por una forma de vida local y federal, que valora más la vida honesta (sencilla y laboriosa,

59 Cfr. OECD, (Consultado el 14/10/13 http://www.oecd.org/pisa/pisaenespaol.htm). En el proyecto PISA se supone que la capacidad lectora, así como la formación matemática y científica, incluyen la capacidad de aplicar procesos y de utilizar los conocimientos en una amplia variedad de contextos. La formación en Matemáticas incluye la capacidad para aplicar los conocimientos, destrezas y comprensiones matemáticas en contextos auténticos. Se considera auténtico un contexto si aparece en las experiencias prácticas y reales de los participantes en situaciones del mundo real. Una parte importante de la definición de formación matemática es hacer y realizar las matemáticas en diversas situaciones. Estas situaciones incluyen la vida personal, la vida escolar, el trabajo y los deportes (o el ocio en general), la comunidad local y la sociedad tal y como se encuentran en la vida cotidiana, y los contextos científicos. Cfr. Autor, artículo, Consultado el 12/10/13 http:/ / www.sectormatematica.cl/ pisa.htm. 
pero no ansiosa por capitalizar) y no los conocimientos formales y la corrupción de la metrópolis. Y esta conducta tiene vigencia todavía hoy, aunque sigan evaluando los aprendizajes con criterios europeos (PISA).

Estas y otras situaciones actuales pueden resultar incomprensibles si no se tiene presente el transfondo histórico del cual proceden. Los acontecimientos históricos presentados en este artículo corroboran la hipótesis de que si bien estos acontecimientos no determinaron por completo las situaciones del aprendizaje, sí las condicionan y permiten también encontrarles un sentido no azaroso.

Las referencias históricas mencionadas hacen razonable sostener, primeramente, la hipótesis de que la educación, en los orígenes de la argentinidad, no tuvo en cuenta a la mayoría de sus habitantes (sobre todo del interior del país), sino a la preparación de una elite porteña, gobernante con mentalidad unitaria. Esta no deseaba estar alejada de los conocimientos producidos por la modernidad naciente en Europa, pero estos conocimientos resultaban ignorados o indiferentes para la mayoría de la población fuera de la metrópoli. Los hombres del interior y, en especial el gauchaje, tenían una cultura y astucia criolla, según la cual lo importante no era aprender mucha ciencia, sino cosas buenas, esto es, tener una conducta honrada y una vida sencilla, como lo expresa el Martín Fierro.

Los documentos históricos -algunos de los cuales mencionamos dentro de los límites de un artículo- permiten interpretar esa época inicial de la educación formal como la expresión de los deseos de una clase de dirigentes, pero no vivida por la población.

En Argentina, con frecuencia, ha entrado en pugna: a) la concepción moral y útil de la educación vivida por la mayoría de sus habitantes del interior; y b) la concepción teórico-investigativa elitista vivida en Buenos Aires, mirando a Europa o a los Estados Unidos de Norteamérica.

El proceso de educación está en función de la vida y debe tender a estar a su servicio; por ello, en ella se debería tener presente tanto a las personas como a la sociedad con sus tradiciones y costumbres, tanto los aspectos teóricos como los prácticos, productos de la experiencia vivida, tanto la dimensión social como la política de la sociedad en la que se vive. La historia de la educación de un país es también maestra para la vida 
de este, a fin de no solo no repetir los mismos errores, sino de aprender de ellos en la búsqueda de un bien común, sin el cual no es pensable una sociedad humana. ${ }^{60}$

\section{REFERENCIAS}

Bonantini, C. Educación y sociedad. Análisis histórico estructural de la escuela media argentina. Rosario: UNR, 1994.

Charamonte, J. C. Nación y Estado en Iberoamérica. Buenos Aires: Sudamericana, 2004.

Delich, F. La crisis en la crisis. Estado, Nación, Sociedad y Mercados en la Argentina contemporánea. Buenos Aires: Eudeba, 2002.

Durán Ramos, T. “Globalización y formación profesional: ¿Nuevas reglas?”. Educación.26, 2 (2002): 107-117.

Echeverría, E. Dogma socialista en Obras Completas. Buenos Aires: Casavalle, 1874. Tomo IV.

Hernández Arregui, J. La formación de la conciencia nacional. Buenos Aires: Hachea, 1970.

Hernández, José. Martín Fierro. Buenos Aires: Quevedo, 2008.

Hillert, F. et al. El sistema educativo argentino. Antecedentes, formación y crisis. Buenos Aires: Cartago, 1985.

Lértora de Mendoza, C. La enseñanza de la filosofía en tiempos de la colonia. Análisis de cursos manuscritos. Buenos Aires: Fundación para la Educación, Ciencia y Cultura, 1979.

Martínez Paz, F. La del alumno. Buenos Aires: M. Gleizer, 1927.

Moreno, Mariano. Vida y memorias del Dr. Mariano Moreno en Memorias y Autobiografías. Buenos Aires: Museo Histórico Nacional, 1910, Tomo II.

Muscará, F. "Las ideas pedagógicas de fines del siglo XIX en los libros de lectura". Educación Cuyo 7 (1998): 165-188.

Narozini, A. et al. El rendimiento escolar en la Argentina. Buenos Aires: Losada, 2002

Puiggrós, A. ¿Qué pasó en la Educación Argentina? Desde la Conquista hasta el Menemismo.

Buenos Aires: Kapelusz, 1996.

Puiggrós, A. Escuela, Democracia y Orden, Historia de la Educación Argentina. Buenos Aires: Editorial Galerna, 1992.

60 Cfr. W. R. Daros, "La educación entendida como formación humana y social” en Invenio, No. 28, (2012):19-28. Disponible en www.williamdaros.wordpress.com 
Rock, D. La Argentina autoritaria. Los nacionalistas, su historia y su influencia en la vida pública. Buenos Aires: Ariel, 1993.

Romero, R. La Argentina en la escuela. Idea de nación en los textos escolares. Buenos Aires: Siglo XXI, 2004.

Saavedra Lamas. Reformas orgánicas de la enseñanza pública: sus antecedentes y fundamentos. Buenos Aires: Peuser, 1916

Salvadores, A. La instrucción primaria entre 1810 y la sanción de la ley 1420. Buenos Aires: Consejo Nacional de Educación, 1941.

Sarmiento, D. F. Obras completas. Buenos Aires: Luz del Día, 1950, Tomo V, X-XII.

Tedesco, Juan Carlos. Educación y sociedad en la Argentina (1880-1945). Buenos Aires, Solar, 1986.

Tenti Fanfani, E. (Comp.) El rendimiento escolar en la Argentina. Buenos Aires: Losada, 2002.

Torrado, S. Estructura social de la Argentina: 1945-1983. Buenos Aires: De la Flor, 1994.

Roberto Daros, William. "Incidencias del proceso histórico en el proceso educativo argentino". Revista Historia de la Educación Latinoamericana. Vol. 16 No, 22, (2014): 51 - 84. 
